to a major Riyadh hospital in the period 1984-1995. Consumption of unpasteurized camel milk was the main source of infection. Arthritis was the dominant symptom in $70 \%$ (Shaalan MA et al. Int J Infect Dis 2002 Sep;6(3):182-6).

\title{
NEUROCUTANEOUS DISORDERS
}

\section{STURGE-WEBER SYNDROME LINKED TO GNAQ MUTATION}

Investigators from Johns Hopkins School of Medicine, the Hugo W Moser Research Institute at Kennedy Krieger, Baltimore; Duke University; and Medical College of Wisconsin, Milwaukee, performed whole-genome sequencing of DNA from paired samples of tissue from 3 persons with the Sturge-Weber syndrome (SWS). GNAQ somatic mosaic mutations were identified in $88 \%$ of participants (23 of 26) with the SWS and from $92 \%$ of participants (12 of 13) with nonsyndromic port-wine stains, but not in any of samples from 4 participants with an unrelated cerebrovascular malformation or in any of the samples from 6 controls. The prevalence of the mutant allele in affected tissues ranged from 1.0 to $18.1 \%$. SWS and port-wine stains are caused by a somatic activating mutation in GNAQ. (Shirley MD, Tang H, Gallione CJ, et al. Sturge-Weber syndrome and port-wine stains caused by somatic mutation in GNAQ. N Engl J Med 2013 May 23;368(21):1971-9). (Reprints: Dr Pevsner, Department of Neurology, Kennedy Krieger Institute, 707 N Broadway, Baltimore, MD 21205. Email: Pevsner@kennedykrieger.org).

COMMENT. These findings identify a single mechanism for the SWS and nonsyndromic port-wine stains and they document a molecular basis for these malformations, causally related to a mutation in a specific gene, GNAQ. The authors hypothesize that the port-wine stains may represent a late origin of the somatic GNAQ mutation in vascular endothelial cells, whereas the SWS mutation may occur earlier in embryotic development. A child born with a port-wine stain in the distribution of the ophthalmic branch of the trigeminal nerve has a $26 \%$ chance of having SWS (Ch'ng S, Tan ST. J Plast Reconstr Aesthet Surg 2008 Aug;61(8):889-93; cited by Shirley MD et al. 2013).

\section{INTRACRANIAL HYPERTENSION}

\section{CLINICAL SPECTRUM OF PSEUDOTUMOR CEREBRI}

Investigators at Erciyes University, Kayseri, Turkey, studied the etiological and clinical features, treatment, and prognosis of pseudotumor cerebri (PTC) in 42 consecutive patients (average age at symptom onset 10 years; range 12 months to 17 years). Girls outnumbered boys, 27 (64\%) to 15 (36\%). Obesity was associated in 11 $(26.2 \%)$ patients. Headache in $32(76 \%)$ was the most common presenting symptom. Headache was acute in $13(31 \%)$, chronic daily in $12(28.8 \%)$, acute recurrent in 4 $(9.5 \%)$, and chronic relapsing in $3(7.1 \%)$. Diplopia occurred in $18(42.9 \%)$, visual loss in $14(33.3 \%)$, vomiting in $15(35.7 \%)$. Papilledema was present in all patients, and VIth cranial nerve paralysis in $8(19.1 \%)$, one bilateral. Mean CSF opening pressure was 350 +/- $96 \mathrm{~mm}$ water. One had venous sinus thrombosis on MR venography. 